\title{
Cross-Cultural and Psychometric Properties Assessment of the Exercise Self-Efficacy Scale in Individuals with Spinal Cord Injury
}

\section{Avaliação Transcultural e das Propriedades Psicométricas da Escala Exercise Self-Efficacy para Indivíduos com Lesão da Medula Espinal}

\author{
Fernando PISCONTI' , Suhaila Mahmoud Smaili SANTOS $\square^{2}$, Josiane LOPES ${ }^{3}$, Jefferson Rosa CARDOSO ${ }^{4}$, \\ Edson Lopes LAVADO ${ }^{2}$ \\ Acta Med Port 2017 Nov;30(11):783-789 - https://doi.org/10.20344/amp.8884
}

\section{ABSTRACT}

Introduction: The Exercise Self-Efficacy scale (ESES) is a reliable measure, in the English language, of exercise self-efficacy in individuals with spinal cord injury. The aim of this study was to culturally adjust and validate the Exercise Self-Efficacy scale in the Portuguese language.

Material and Methods: The Exercise Self-Efficacy scale was applied to 76 subjects, with three-month intervals (three applications in total). The reliability was appraised using the intra-class correlation coefficient and Bland-Altman methods, and the internal consistency was evaluated using Cronbach's alpha. The Exercise Self-Efficacy scale was correlated with the domains of the Quality of life Questionnaire SF-36 and Functional Independence Measure and tested using the Spearman rho coefficient.

Results: The Exercise Self-Efficacy scale-Brazil presented good internal consistency (alpha 1 = 0.856; alpha 2 = 0.855 ; alpha 3 = 0.822 ) and high reliability in the test-retest (intra-class correlation coefficient $=0.97$ ). There was a strong correlation between the Exercise Self-Efficacy scale-Brazil and the SF-36 only in the functional capacity domain (rho $=0.708$ ). There were no changes in Exercise Self-Efficacy scale-Brazil scores between the three applications $(p=0.796)$.

Discussion: The validation of the Exercise Self-Efficacy scale questionnaire permits the assessor to use it reliably in Portuguese speaking countries, since it is the first instrument measuring self-efficacy specifically during exercises in individuals with spinal cord injury. Furthermore, the questionnaire can be used as an instrument to verify the effectiveness of interventions that use exercise as an outcome.

Conclusion: The results of the Brazilian version of the Exercise Self-Efficacy scale support its use as a reliable and valid measurement of exercise self-efficacy for this population.

Keywords: Motor Activity; Self Efficacy; Spinal Cord Injuries/rehabilitation; Validation Studies

\section{RESUMO}

Introdução: O instrumento Exercise Self-Efficacy scale (ESES) é fiável, na língua inglesa, para medir a autoeficácia em exercícios em indivíduos com lesão medular. O objetivo do estudo foi adaptar transculturalmente e validar a escala ESES para a língua Portuguesa. Material e Métodos: O Exercise Self-Efficacy scale foi aplicado três vezes em 76 indivíduos, a cada três meses. A fiabilidade foi avaliada pelo coeficiente de correlação intraclasse de Bland e Altman, e a consistência interna pelo alfa de Cronbach. O Exercise Self-Efficacy scale foi correlacionado com os domínios do Questionário de Qualidade de Vida SF-36 e da Medida de Independência Funcional e avaliado pelo rho de Spearman.

Resultados: O Exercise Self-Efficacy scale-Brasil apresentou boa consistência interna (alpha 1 = 0,856; alpha 2 = 0,855 e alpha 3 = 0,822 ) e alta fiabilidade no teste-reteste (coeficiente de correlação intraclasse $=0,97$ ). Houve correlação forte do Exercise Self-Efficacy scale-Brasil somente com o domínio Capacidade Funcional do SF-36 (rho = 0,708). Não houve mudança nas pontuações do Exercise Self-Efficacy scale-Brasil entre as três aplicações $(p=0,796)$

Discussão: A validação do Exercise Self-Efficacy scale permite que este seja utilizado nos países de língua portuguesa de forma fiável, pois representa o primeiro instrumento específico para o estudo da auto-eficácia em exercícios em indivíduos com lesão medular e, ainda, ser utilizado como instrumento para verificar a efetividade de intervenções que utilizem exercício como desfecho.

Conclusão: A versão brasileira da Exercise Self-Efficacy scale é válida e fiável para avaliação da autoeficácia em exercícios para essa população.

Palavras-chave: Atividade Motora; Autoeficácia; Estudos de Validação, Lesões da Medula Espinal/reabilitação

\section{INTRODUCTION}

The spinal cord acts as a bidirectional conduction pathway between the brain and the motor, sensory and autonomic regions of the human body. As the functions of the spinal cord differ in regard to the segment and structure,

an injury may cause a variety of types and degrees of dysfunction in the human body. ${ }^{1}$ The higher on the spinal column the spinal segment involved and the greater the extent of the damage, the less muscle mass there is

\footnotetext{
1. Programa de Pós-Graduação em Ciências da Reabilitação. Universidade Estadual de Londrina - Universidade Norte do Paraná. Londrina. Brasil.

2. Departamento de Fisioterapia. Universidade Estadual de Londrina. Londrina. Brasil.

3. Laboratório de Biomecânica e Epidemiologia Clínica. Universidade Estadual de Londrina. Londrina. Brasil.

4. Programa de Pós-Graduação em Ciências da Saúde. Universidade Estadual de Londrina. Londrina. Brasil.

$\square$ Autor correspondente: Suhaila M. Smaili Santos. suhailaneuro@gmail.com

Recebido: 22 de fevereiro de 2017 - Aceite: 04 de agosto de 2017 | Copyright $\odot$ Ordem dos Médicos 2017
} 
available for physical activities and, therefore, for functional independence. $^{2}$

With improved medical care, life expectancy following a spinal cord injury (SCl) has increased. ${ }^{3}$ However, this depends not only on advances in medical care, but also on the prevention of secondary complications that can lead to death. ${ }^{4}$ In fact, many causes of morbidity and mortality in individuals with $\mathrm{SCl}$ result from physical inactivity-related diseases, such as cardiovascular diseases and diabetes mellitus. ${ }^{5}$

Sedentary behavior is a common consequence in individuals with $\mathrm{SCl}$ that may compromise their quality of life and social participation, thereby exacerbating the impact of the damage. ${ }^{5,6}$ These facts underline the importance of promoting physical activity to improve health and wellbeing in individuals with $\mathrm{SCl}$, particularly as, for some time, these individuals have been classified as exhibiting lower levels of physical activity in the general population. ${ }^{7-9}$

In Brazil, it is estimated that there are more than six thousand new cases of $\mathrm{SCl}$ each year, making it important to adopt measures that reduce potential secondary complications to the injury and, therefore, encourage a healthier lifestyle in this population. ${ }^{10}$

The idea of individuals with $\mathrm{SCl}$ adopting physical exercise programs is not new. In the literature, studies published in recent decades have pointed out the need for these individuals, according to their individual ability, to adopt an exercise routine as part of a healthy lifestyle. ${ }^{11-14}$

Despite the large quantity of research in the field of exercise science, little is known about the possible barriers to participation in physical exercise for people with physical disabilities and still less is known about the barriers for individuals with $\mathrm{SCl} .{ }^{15}$

One of the concepts often used in research on health promotion in the general population is self-efficacy. The term is derived from cognitive social psychology and was developed in the 1970s by Albert Bandura, who defined it as an individual's confidence in his/her own ability to combine the cognitive, motivational, affective and behavioral resources necessary to achieve a goal, deal with a particular situation or perform a specific task successfully. ${ }^{16,17}$ Selfefficacy has been studied in fields other than psychology, including research in the areas of education, health and sport. ${ }^{18}$

In order to discover the best intervention targeting the adherence of individuals with $\mathrm{SCl}$ to the practice of regular exercise, it is first necessary to identify the factors that can be modified and act as a potential barrier for these individuals. ${ }^{19}$ Many factors are related to the participation of an individual in regular physical exercise and selfefficacy is a modifiable factor that is considered to be the most consistent behavior with respect to the adoption and participation of adults without a disability in physical activity or regular physical exercise..$^{19,20}$

In the absence of a specific instrument for the study of self-efficacy for exercise in individuals with $\mathrm{SCl}$, in 2007 Kroll and colleagues published the first assessment tool for measuring self-efficacy in exercise for this population in the English language, the Exercise Self-Efficacy Scale (ESES). ${ }^{21}$ Following its development, the ESES was crossculturally adapted and validated for the Netherlands in 2013 by Nooijen et al, ${ }^{22}$ where it is considered a valid and reliable instrument.

In Brazil, the ESES has not yet been adapted and validated for the assessment of exercise self-efficacy in individuals with $\mathrm{SCl}$. Thus, the objective of this study was the cross-cultural adaptation and validation of the ESES instrument for the Portuguese language and Brazilian culture, testing its reliability and responsiveness over six months following the first application.

\section{MATERIAL AND METHODS \\ Ethical considerations}

First, the study obtained authorization from the author of the ESES and the local Committee for Ethics in Research (013/2012). All participants signed an informed consent form after being fully informed about the study objectives and the procedures to which they would be submitted.

\section{Recruitment of participants and sample size}

The study included 86 individuals, aged 18 - 70 years old, with complete or incomplete spinal cord injury segments C5 and L2 who may or may not have attended physical therapy services in the city and region of the study. All participants had the ability to read in the Portuguese language. Those who refused to sign the informed consent form or were community ambulators were excluded from the study.

The estimated study sample size was 72 individuals, considering a prevalence of $0.18 \%$ in Brazil of individuals with $\mathrm{SCl}$ and a standard error of $1 \%$. We also adopted the recommendation for validation studies, which advocates the use 5 - 10 subjects per item in the questionnaire. 23,24

The research locations included the Neuro-Functional Adult Outpatient Clinic of a local hospital, the trauma department of the local clinical hospital, and a private physical therapy clinic in the city of the study and the residences of the participants. The survey began in April 2012 and ended in August 2013.

\section{Instruments}

The method proposed by Beaton et al $(2000)^{25}$ was adopted in the study; the ESES was translated from English into Portuguese by two bilingual translators, who produced two independent versions, V1 and V2. Versions V1 and V2 were then submitted to evaluation by two doctors and practitioners in the area of neurological physical therapy, who produced a consensual version in Portuguese, V3. The consensual V3 version was translated back into English by two professional English translators, who produced versions VR1 and VR2. The VR1 and VR2 versions were compared with the original text of the instrument in English by the two aforementioned physiotherapists, who produced a consensual pre-final version for use in the pretest.

The pre-final version of the ESES was administered to a 
sample of 10 individuals, in the form of self-application and the time needed to complete the instrument was recorded. On completion of the pre-final ESES, the evaluator asked the participants if they had any queries or suggestions. Taking into account the reports of the 10 individuals, versions VR1, VR2 and V3 and the text of the original instrument, we obtained the final version of the ESES in Portuguese.

The final version of the ESES was administered to 76 subjects, of whom 20 participated in the assessment of intraand inter-rater reliability as follows: initial application of the ESES by evaluator A (ESES-1); application of the ESES by evaluator $B$ ten minutes after evaluator A (ESES-2); and the reapplication of the ESES by evaluator $A$ between 72 and 120 hours after the first application (ESES-3). Following the application of the ESES-3, the scale was reapplied to the same 20 participants twice more by evaluator $A$ at threemonth intervals.

Parallel to the applications of the ESES to the 20 individuals involved in assessing the reliability of the instrument, evaluator A performed three applications with the remaining 56 individuals (ESES-1, ESES-2 and ESES3 ), at three-month intervals. Only one individual did not complete the final application.

To establish the socio-clinical aspects of the participants, five questions were asked together with the application of the ESES, including neurological level, time since the

Table 1 - Characteristics of the sample from the transcultural adaptation $(n=10)$

\begin{tabular}{lc}
\hline Characteristics & \\
\hline Age (years) & 42.72 \\
$\bar{x}$ & 16.91 \\
$\mathrm{SD}$ & \\
Gender (n (\%)) & $2(20)$ \\
Feminine & $8(80)$ \\
Masculine & \\
Level of Education $\mathrm{n}(\%)$ & $0(0)$ \\
Incomplete secondary school & $4(40)$ \\
Complete secondary school & $1(10)$ \\
Incomplete high school & $3(30)$ \\
Complete high school & $1(10)$ \\
Incomplete higher education & $1(10)$ \\
Complete higher education & \\
Level of injury $n(\%)$ & $5(50)$ \\
Cervical (C5 - C8) & $5(50)$ \\
Thoracolumbar (T1 - L2) & \\
Time since injury (months) & $10(100)$ \\
Median & $0(0)$ \\
Quartiles (1 ${ }^{\text {st }}$ and 3 rd $)$ & $(76-166)$ \\
Etiology $n$ (\%) & \\
Nraumatic & \\
\hline
\end{tabular}

$\overline{\bar{x}}$ : Mean; SD: Standard deviation injury, cause of the injury, level of education and date of birth. In addition to the five questions and the ESES, on different days for the ESES, the researcher applied the Generic Assessment Questionnaire of Quality of Life (SF36) and the Functional Independence Measure (FIM), for the analysis of possible correlations between the ESES and the domains of these instruments.

\section{Statistical analysis}

Data were summarized by mean and standard deviation or median and quartiles $(25 \%-75 \%)$. The internal consistency was assessed through the Cronbach's alpha coefficient. To test intra- and inter-reliability, the intraclass correlation coefficient (ICC) and their respective confidence intervals of $95 \%$ and the Bland-Altman agreement method were used.

Responsiveness was assessed by analysis of variance (ANOVA) for repeated measures. The Mauchly test of sphericity was applied and, where this was violated, technical corrections were performed using the Greenhouse-Geisser test. Construct validity was analyzed using Spearman's correlation coefficient (rho). Strong correlations were defined as rho $\geq 0.70$. Statistical significance was set at $5 \%$ and all analyses were performed with SPSS version

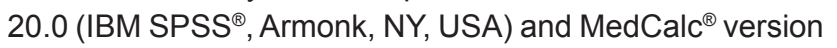
11.1.1.0.

Table 2 - Characteristics of the sample in the validation stage $(\mathrm{n}=76)$

\begin{tabular}{lc}
\hline Characteristics & \\
\hline Age (years) & 39 \\
Median & $(29.25-45.75)$ \\
Quartiles & \\
Gender (n (\%)) & $10(13.2)$ \\
Feminine & $66(86.8)$ \\
Masculine & \\
Level of Education $\mathrm{n}(\%)$ & $25(33)$ \\
Incomplete secondary school & $10(13)$ \\
Complete secondary school & $8(10)$ \\
Incomplete high school & $22(29)$ \\
Complete high school & $5(7)$ \\
Incomplete higher education & $6(8)$ \\
Complete higher education & \\
Level of injury $n(\%)$ & $10(13)$ \\
Cervical (C5 - C8) & $66(87)$ \\
Thoracolumbar (T1 - L2) & \\
Time since injury (months) & 108 \\
Median & $(60-204)$ \\
Quartiles (1 ${ }^{\text {st }}$ and $3^{\text {rd }}$ ) & \\
Etiology $n(\%)$ & $(82)$ \\
Traumatic & \\
Non-traumatic & \\
\hline
\end{tabular}


In the stage of transcultural adaptation of the instrument, the average age of the 10 participants was 42.7 years with a predominance of males, who had completed secondary education and suffered from chronic SCI. There were a similar number of individuals with paraplegia and tetraplegia and the etiology of the injury was traumatic in all the subjects. (Table 1).

In the validation stage of the ESES-Brazil, 76 individuals were evaluated. This sample was composed predominantly of male individuals with incomplete secondary education and chronic $\mathrm{SCl}$ of traumatic etiology. Unlike the adaptation sample, the validation sample was composed predominantly of individuals with injury in the thoracic or lumbar spinal segments. (Table 2 ).

The intra- and inter-rater reliability of the Brazilian version of the ESES, measured through the intraclass correlation coefficient (ICC) and Bland-Altman agreement method, was high, as shown in Table 3.

The values of Cronbach's alpha found between the three applications of the ESES had values above 0.70 (Table 4). Among the three applications of the Brazilian version of the ESES with the 76 participants, there were no statistically significant differences in the scores for the scale and an asymptotic significance equal to 0.796 was found.

The quality of the data, evaluated by the occurrence of missing data and the floor and ceiling effects, was good, with only one participant not completing the third application of the ESES (Table 5).

Among the domains of the SF-36 questionnaire and the FIM domains, there was strong correlation with the ESES only for the functional capacity domain (rho $=0.708$ ). Regarding the other domains of the SF-36 and the FIM, only moderate and weak correlations were found.

\section{DISCUSSION}

Spinal cord injuries are highly debilitating and can lead to physical, psychological, and social problems for patients and their families. ${ }^{26}$ Individuals with $\mathrm{SCl}$ who have higher self-efficacy have higher life satisfaction, greater psychological well-being, better mental health and less anxiety and depression. ${ }^{27}$ Besides, there is evidence in the literature suggesting that self-efficacy is related to physical activity and has an important component of function. ${ }^{28}$ Therefore, it is important to use an instrument that evaluates the self-efficacy of individuals with $\mathrm{SCl}$ due to its impact on the quality of life of this population.

The aim of the study was to translate the ESES instrument into the Portuguese language, adapt it to Brazilian culture and assess its reliability in the measurement of selfefficacy for exercise in individuals with spinal cord injuries. Among the characteristics of the individuals participating in the validation study of the ESES-Brazil, there was a predominance of young adult males. These data agree with those of Brazilian statistics regarding the gender and age group with the highest incidence of spinal cord injury. ${ }^{10,29}$

As in the Dutch version, ${ }^{22}$ the Brazilian version of the ESES, included a larger number of individuals with SCl of traumatic etiology, with predominance of lesions in the thoracic or lumbar segments. This predominance of individuals with paraplegia caused by trauma contrasts with what is indicated by the statistics for both Brazil and other countries. ${ }^{10,29-31}$ From the second application, the form of application of the ESES-Brazil differed from that of the Dutch version for some of the participants. In the Dutch study, the ESES was applied personally by the researchers,

Table 3 - Reliability test ICC and Bland-Altman $(n=20)$

\begin{tabular}{|c|c|c|c|c|c|c|}
\hline & \multicolumn{3}{|c|}{$\begin{array}{c}\text { ICC } \\
\text { (random effect }- \text { one factor) }\end{array}$} & \multicolumn{3}{|c|}{ Bland-Altman } \\
\hline & ICC & [Cl 95\%] & $\bar{d}$ & $\mathrm{Cl} 95 \%$ of $\bar{d}$ & $\mathrm{SD}$ of $\bar{d}$ & LA 95\% \\
\hline Intra-rater & 0.97 & [0.92; 0.99] & 0.10 & $-1.01 ; 1.21$ & 2.36 & $-4.53 ; 6.64$ \\
\hline Interrater & 0.99 & {$[0.97 ; 0.99]$} & -0.15 & $-0.82 ; 0.52$ & 1.42 & $-4.1 ; 3.8$ \\
\hline
\end{tabular}

ICC: Intra-class correlation coefficient; CI 95\%: Confidence interval of 95\%; $\bar{d}$ : Mean difference; SD of $\bar{d}$ : Standard deviation of the difference; LA: Limits of agreement

Table 4 - Cronbach's alpha in the three applications of the ESES-Brazil

\begin{tabular}{lccc}
\hline & Cronbach's alpha & Number of items & n \\
\hline ESES-1 & 0.856 & 10 & 76 \\
ESES-2 & 0.855 & 10 & 76 \\
ESES-3 & 0.822 & 10 & 75 \\
\hline
\end{tabular}

ESES-1: Initial application; ESES-2: Application after three months; ESES-3: Application after six months

Table 5 - Floor and ceiling effects

\begin{tabular}{|c|c|c|c|c|c|c|}
\hline & \multicolumn{2}{|c|}{$\begin{array}{c}\text { Floor effect } \\
5 \%\end{array}$} & \multicolumn{2}{|c|}{$\begin{array}{c}\text { Ceiling effect } \\
95 \%\end{array}$} & \multicolumn{2}{|c|}{ Total } \\
\hline & $\mathrm{n}$ & $\%$ & $\mathrm{n}$ & $\%$ & $n$ & $\%$ \\
\hline Initial & 3 & 3.94 & 4 & 5.26 & 7 & 9.21 \\
\hline 3 months & 3 & 3.94 & 4 & 7.88 & 9 & 11.84 \\
\hline 6 months & 3 & 3.94 & 4 & 5.26 & 7 & 9.21 \\
\hline
\end{tabular}


both in the first and the second applications. ${ }^{22}$ In the present study, the ESES-1 was completed personally by each of the participants and, in the second and third applications, the individuals completed the scale either personally or by telephone interview.

The Brazilian version of the ESES, as well as the original $^{21}$ and Dutch ${ }^{22}$ versions, presented good internal consistency. In the original version, Cronbach's alpha for a single application of the ESES was $0.87 .{ }^{21}$ In the Dutch version the internal consistency was assessed at two points in time (ESES-1 and ESES-2), with an interval of two weeks between assessments. The values presented were $\alpha 1=$ 0.90 and $\alpha 2=0.88 .^{22}$

In the Brazilian version, the ESES was applied three times at three-month intervals and values above 0.80 were found in all three applications. The scores in the three applications of the ESES-Brazil showed no statistically significant differences ( $p=0.796$ ), thus indicating good responsiveness of the Brazilian version in the sample studied. Due to the prevalence of individuals with chronic $\mathrm{SCl}$, it was not possible to determine whether the instrument is responsive for individuals with $\mathrm{SCl}$ during the early rehabilitation phase.

The ESES-Brazil presented high reliability, as evidenced by the values of Cronbach's alpha. The reliability analysis in this study was performed differently to that of the original ${ }^{21}$ and Dutch ${ }^{22}$ versions. In the original ${ }^{21}$ version, reliability was analyzed through internal consistency using Cronbach's alpha and the split-half method, as this method is an option for test-retest that requires a single application of the questionnaire. In the Dutch ${ }^{22}$ version, reliability was assessed through internal consistency using Cronbach's alpha and test-retest reliability through the ICC.

The present study followed the suggestion of Rankin and Stokes (1998), who recommended that reliability be assessed through the ICC and Bland-Altman statistical tests, which complement each other and, when used separately, do not provide a reliable interpretation of reliability. ${ }^{32}$

In the studies by Kroll et al (2007) ${ }^{21}$ and Nooijen et al $(2013)^{22}$, the ESES was correlated with the English and Dutch versions of the General Self-Efficacy Scale (GSES), an instrument formulated to assess the perception of an individual's optimism to confront situations of everyday difficulties. A moderate and statistically significant correlation was found in both studies between the ESES and the GSES.

The correlations were assessed between the Brazilian version of the ESES and the domains of the SF-36 and the FIM; a strong correlation was found only with the Functional Capacity domain of the SF-36 (rho = 0.708). The option to correlate the ESES with the SF-36 and the FIM was adopted in this study as an alternative to the Brazilian version of the GSES by the inexistence of other questionnaires that assess the subjective perception of the individuals about the practice of physical exercise. For these reasons, moderate and weak correlations were expected with the instruments used, as these were created for specific populations.
It should be noted that, although these instruments present weaknesses in the application for individuals with $\mathrm{SCl}$, they are widely used as an assessment measure. ${ }^{33-35}$ This option was chosen as we predicted that the two questionnaires would generate a better understanding of the profile of the participants, since they assess both functional aspects and the general state of health, rather than evaluating only the perception of optimism of individuals to cope with everyday difficult situations, as in the GSES.

The practice of physical activity was addressed in the original ${ }^{21}$ and Dutch ${ }^{22}$ studies through one or two questions. In the study by Krolletal (2007), ${ }^{21}$ the practice of physical exercise was assessed among the participants by asking them whether they had exercised in the 12 months prior to the study, either in their homes, at the gym, or both, or if they had not exercised. In spite of the questions, the differentiation between physical activity, physical exercise, exercise type, frequency and intensity were not addressed. In the Dutch version, apart from individuals who exercised in daily physical therapy sessions, the other participants were asked whether, at the time of the study, they engaged into sports, which sport they practiced and the number of hours for which they participated in the activity. ${ }^{22}$ Both in the original ${ }^{21}$ and in the Dutch ${ }^{22}$ studies, the criteria used for classifying individuals as practicing exercise or not are not mentioned, nor is their conception of structured physical activity. Likewise, there is no mention of the criteria held by agencies such as the World Health Organization. Even though in the analysis both studies aimed to assess possible differences in the ESES scores of individuals considered practitioners and non-practitioners of physical exercise, the adopted criteria were not clear.

According to the American College of Sports Medicine, the definitions of physical activity and physical exercise are not the same. Physical activity is defined as any bodily movement produced by skeletal muscles that results in energy expenditure above the at-rest level (baseline) and physical exercise is defined as a physical activity that is planned, structured and repetitive, with the final or intermediate objective of maintaining or improving physical fitness. ${ }^{36}$

In the general population, studies show that time restriction and lack of motivation are the main reasons individuals have for not incorporating physical activity into everyday life. ${ }^{15}$ In contrast, the limitations of individuals with $\mathrm{SCl}$ regarding the practice of physical activity are attributed to functional impairment caused by the injury and the individual factors related to secondary complications. ${ }^{11,15}$

Although the literature suggests that external barriers could be important factors related to non-adherence to regular physical activity, there is a growing understanding that complications secondary to the injury, e.g., functionality and attitudinal factors, such as self-efficacy and motivation, have an important role in the maintenance of regular physical activity. ${ }^{11,15}$

The Brazilian version of the ESES did not assess the practice of physical exercise in the study participants, 
as this analysis should be conducted carefully and with greater methodological rigor than that adopted in the original $^{21}$ and Dutch ${ }^{22}$ studies. As such, it was decided that this study should be focused on the validation of the ESES in the Portuguese language and that analyses of possible differences in the scores of the ESES-Brazil for individuals should be carried out, appropriately classified as practitioners or non-practitioners of physical exercise in future studies. This is a limitation of the study.

Future research should assess the psychometric properties and responsiveness of the ESES-Brazil in regard to individuals with spinal cord injuries during the initial rehabilitation phase. In addition, possible differences in ESES-Brazil scores should be evaluated, differentiating individuals with $\mathrm{SCl}$ who are practitioners of structured adapted sports from those individuals who only engage in physical activity that is linked to everyday functional demands.

\section{CONCLUSION}

The Brazilian version of the Exercise Self-Efficacy Scale
(ESES-Brazil) for individuals with spinal cord injury is a valid, reliable and internally consistent instrument.

\section{PROTECTION OF HUMANS}

The authors declare that the procedures were in agreement by the Clinical Research and Ethics Committee and to the Helsinki Declaration. All patients provided informed consent form to the participation in the study.

\section{DATA CONFIDENTIALITY}

The authors declare having followed the protocols in use at their working center regarding patients' data publication.

\section{CONFLICTS OF INTEREST}

The authors declared no potential conflicts of interest with respect to the research, authorship, and/or publication of this article.

\section{FUNDING SOURCES}

None.

participation in physical activity following spinal cord injury: a qualitative study. Phys Ther. 2004;84:496-509.

REFERENCES
1. Jacobs PL, Nash MS. Exercise recommendations for individuals with spinal cord injury. Sports Med. 2004;34:727-51.

2. Davis GM. Exercise capacity of individuals with paraplegia. Med Sci Sports Exerc. 1993;25:423-32.

3. DeVivo MJ, Shewchuk RM, Stover SL, Black KJ, Go BK. A crosssectional study of the relationship between age and current health status for persons with spinal cord injuries. Paraplegia. 1992;30:820-7.

4. Krause JS, Carter RE, Pickelsimer E. Behavioral risk factors of mortality after spinal cord injury. Arch Phys Med Rehabil. 2009;90:95-101.

5. Garshick E, Kelley A, Cohen SA, Garrison A, Tun CG, Gagnon D, et al. A prospective assessment of mortality in chronic spinal cord injury. Spinal Cord. 2005;43:408-16.

6. Noreau L, Shepard RJ. Spinal cord injury, exercises and quality of life. Sports Med. 1995;20:226-50.

7. Hicks AL, Martin KA, Ditor DS, Latimer AE, Craven C, Bugaresti J, et al. Long-term exercise training in persons with spinal cord injury: effects on strength, arm ergometry performance and psychological well-being. Spinal Cord. 2003;41:34-43.

8. Ginis KA, Latimer AE, Arbour-Nicitopoulos KP, Buchholz AC, Bray SR, Craven BC, et al. Leisure time physical activity in a population-based sample of people with spinal cord injury part I: demographic and injuryrelated correlates. Arch Phys Med Rehabil. 2010;91:722-8.

9. van den Berg-Emons RJ, Bussmann JB, Haisma JA, Sluis TA, van der Woude LH, Bergen MP, et al. A prospective study on physical activity levels after spinal cord injury during inpatient rehabilitation and the year after discharge. Arch Phys Med Rehabil. 2008;89:2094-101.

10. Ministério da Saúde. Brasília: Portal da Saúde. Saúde da pessoa com deficiência. [accessed 2013 May 03]. Available from: http://portalsaude. saude.gov.br/index.php/o-ministerio/principal/secretarias/sas/saudeda-pessoa-com-deficiencia.

11. Nash MS. Exercise as a health-promoting activity following spinal cord injury. J Neurol Phys Ther. 2005;29:87-103.

12. Fernhall B, Heffernan K, Jae SY, Hedrick B. Health implications of physical activity in individuals with spinal cord injury: a literature review. J Health Hum Serv Adm. 2008;30:468-502.

13. Nooijen CF, de Groot S, Postma K, Bergen MP, Stam HJ, Bussmann JB, et al. A more active lifestyle in persons with a recent spinal cord injury benefits physical fitness and health. Spinal Cord. 2012;50:320-3.

14. Hicks AL, Martin GK, Pelletier CA, Ditor DS, Foulon B, Wolfe DL. The effects of exercise training on physical capacity, strength, body composition and functional performance among adults with spinal cord injury: a systematic review. Spinal Cord. 2011;49:1103-27.

15. Levins SM, Redenbach DM, Dyck I. Individual and societal influences on
16. Bandura A. Self-efficacy: Toward a unifying theory of behavioral change. Psychol Rev. 1977;84:191-215.

17. Bandura A. Adolescent development from an agentic perspective. In: Pajares F, Urdan T, editors. Self-efficacy beliefs of adolescents. Greenwich: Information Age Publishing; 2006. p. 1-43.

18. Chia-Huei Wu. Factor analysis of the general self-efficacy scale and its relationship with individualism/collectivism among twenty-five countries: application of multilevel confirmatory factor analysis. Pers Individ Dif. 2009;46:699-703.

19. Kehn M, Kroll T. Staying physically active after spinal cord injury: a qualitative exploration of barriers and facilitators to exercise participation.

20. Trost SG, Owen N, Bauman AE, Sallis JF, Brown W. Correlates of adult's participation in physical activity: review and update. Med Sci Sports Exerc. 2002;34:1996-2001.

21. Kroll T, Kehn M, Ho PS, Groah S. The SCI Exercise Self-Efficacy Scale (ESES): development and psychometric properties. Int J Behav Nutr Phys Act. 2007;4:34.

22. Nooijen CF, Post MW, Spijkerman DC, Bergen MP, Stam HJ, van den Berg-Emons RJ. Exercise self-efficacy in persons with spinal cord injury: psychometric properties of the Dutch translation of the exercise selfefficacy scale. J Rehabil Med. 2013;45:347-50.

23. Hair JF, Tatham RL, Anderson RE, Black W. Análise multivariada de dados. Porto Alegre: Bookman; 2005.

24. Kerlinger FN. Foundations of behavioral research. $3^{\text {rd }}$ ed. New York: Holt, Rinehard and Winston; 1986.

25. Beaton DE, Bombardier C, Guillemin F, Ferraz MB. Guidelines for the process of cross-cultural adaptation of self-report measures. Spine. 2000;25:3186-91.

26. Kim JY, Cho E. Evaluation of a self-efficacy enhancement program to prevent pressure ulcers in patients with a spinal cord injury. Jpn J Nurs Sci. 2017;14:76-86.

27. Cijsouw A, Adriaansen JJ, Tepper M, Dijksta CA, van Linden S; ALLRISC, al. Associations between disability-management self-efficacy, participation and life satisfaction in people with long-standing spinal cord injury. Spinal Cord. 2017;55:47-51.

28. Hill JN, Etingen B, Miskevics S, LaVela SL. Correlates of self-reported physical function in individuals with spinal cord injuries and disorders: does self-efficacy matter? Spinal Cord. 2017. (in press).

29. Portal da Rede Sarah de Hospitais de Reabilitação. Brasília: Programas de Prevenção. [accessed 2013 Oct 13]. Available from: http://www. BMC Public Health. 2009;9:168. 
sarah.br/programas-educacionais/estudos-epidemiologicos/.

30. Wyndaele M, Wyndaele JJ. Incidence, prevalence and epidemiology of spinal cord injury: what learns a worldwide literature survey? Spinal Cord. 2006;44:523-9.

31. New PW, Cripps RA, Bonne LB. Review. Global maps of non-traumatic spinal cord injury epidemiology: towards a living data repository. Spinal Cord. 2014;52:97-109.

32. Rankin G, Stokes M. Reliability of assessment tools in rehabilitation: an illustration of appropriate statistical analyses. Clin Rehabil. 1998;12:18799.

33. Conrad C, Chamlian TR, Ogasowara MS, Pinto MA, Masiero D, et al. Tradução para o português, adaptação cultural e validação do
Questionário de Avaliação de Próteses. J Vasc Bras. 2015;14:110-14.

34. Juvenal EA, Savordelli CL. Effectiveness of the cycle ergometer in cardiovascular conditioning of spinal cord injured patients. Rev Soc Bras. 2016;14:151-5

35. Neto MG, Castro MF. Study of functional independence and quality of life among active and sedentary elderly. Rev Bras Med Esporte. 2012;18:234-7.

36. Garber CE, Blissmer B, Deschenes MR, Franklin BA, Lamonte MJ, Lee IM, et al. Quantity and quality of exercise for developing and maintaining cardiorespiratory, musculoskeletal, and neuromotor fitness in apparently healthy adults: guidance for prescribing exercise. Med Sci Sports Exerc. 2011;43:1334-59. 